\title{
Journal of Surgery
}

[Jurnalul de Chirurgie]

\section{The role of Scientific Societies in professional development: training programs of the Italian Society of Emergency and Trauma Surgery (SICUT)}

\author{
Franco Stagnitti ${ }^{1}$, Andrea Stagnitti ${ }^{2}$ \\ 1 Rome "Sapienza" University \\ 2 St. John the Baptist Rome Hospital
}

\begin{abstract}
.
In Italy and throughout Europe training in emergency surgery has been reduced to a minimum. Our British colleagues drew attention to this a long time ago, denouncing professional and existential problems of surgeons who do not feel able to adequately manage all types of surgical emergencies. They demand better practical training and insist that emergency surgery should be reserved for specialists in the field. But who will? train them if academic training programs in emergency surgery have been eliminated and not replaced by programs like "Acute Care Surgery" training in the United States. Y The recently introduced European Work Time Directive (EWTD) reduces by $50 \%$ the amount of time tutors and trainees can dedicate to professional activities. As a result, public and private institutions, cultural and professional associations, trade union representatives, specialty organizations, scientific societies and others have been

proposing and organizing all kinds of events, many of which have increased the financial burden placed on individual doctors. The Royal College of Surgeons has calculated that the cost of continuing or completing postgraduate training in surgery is currently ca. $£ 3360$ (ranging from $£ 2735-20780$ ). This plays a significant part in the loss of interest in surgery shown by young doctors. This is especially true of emergency surgery because of the unsatisfactory lifestyle, low salaries, and the greater degree of responsibility and risk of medico-legal problems associated with this subspecialty. We believe that scientific societies should attempt to compensate for the deficit of institutional training by providing high-quality, inexpensive alternatives. In the past few years various societies, particularly Anglo-Saxon ones, have offered live surgery course in trauma surgery (Advanced trauma operative management [ATOM], definitive surgical trauma care [DSTC], advanced surgical skills for exposure in trauma [ASSET]) and courses on the theory and practice of the first approach to patients who need emergency care. The European Union of Medical Specialists (UEMS) has developed certification courses in emergency surgery upon completion of which participants obtain a European certificate of professional competence in emergency surgery and the European Society for Trauma and Emergency Surgery (ESTES) has done the same as regards professional competence in specific diagnostic and treatment procedures in an emergency setting. The Italian Society of Emergency and Trauma Surgery (SICUT) after having validated the best courses from the UK and USA and proposed their use in Italy, and directly imported the DSTC, began to organize its own residential courses and other training initiatives intended especially for young surgeons. These initiatives include masters' degrees, e-learning courses, single-topic webinars. Recent additions are live surgery courses on animal model as well as a course on lifesaving procedures on human cadavers, all of which are intended to improve the manual skills and intraoperative decision-making skills of both young and more experienced surgeons.
\end{abstract}

Key words: emergency surgery, training programs, professional development

\section{Introduction}

In recent years, in Italy and throughout the European Union and also to some extent in the United States, there has been a continual reduction in institutional training programs in surgery, especially
Corresponding author: Franco Stagnitti: franco.stagnitti@gmail.com Received: July 17, 2021; Accepted: August 30, 2021; Published September 30,2021

Citation: Stagnitti F., Stagnitti A.: The role of Scientific Societies in professional development: training programs of the Italian Society of Emergency and Trauma Surgery (SICUT). Jurnalul de chirurgie [Journal of Surgery]. 2021; 17(3): 148 - 153. DOI:10.7438/JSURG.2021.03.01

Copyright: ( 2021 Stagnitti F.et al. This is an open-access article distributed under the terms of the Creative Commons Attribution License, which permits unrestricted use, distribution, and reproduction in any medium, provided the original author and source are credited 
emergency surgery. The quality and quantity of instruction in theoretical knowledge and practical skills began to decline when emergency surgery was joined to general surgery.

This occurred when general surgery began to lose its traditional identity as "the all-encompassing mother discipline ", disintegrating into a myriad of subspecialties, due to the impact of technical and technological progress (1). This fragmentation of general surgery was mirrored by changes in surgical training.

In the long term, this has led to a series of problems with training programs with the result that newly graduated surgeons do not have enough training in surgery. As a direct consequence of this a significant percentage of young surgeons, $25 \%$ in the UK (2), are not considered able to practice without supervision. Even in the USA $66 \%$ of surgeons graduating from residency programs are considered to be unable to operate for 30 minutes of a major

procedure without supervision (3). Moreover, it is undisputed that $80 \%$ of newly qualified surgeons are aware that their training is inadequate (2).

\section{training}

\section{Current causes of inadequate}

There are many reasons for the current decline in the quality of and interest in training programs at academic institutions. These range from continually increasing costs to reduced time dedicated to training, from growing difficulties in organizing adequate training programs to the resultant lack of appeal of these programs. Young doctors are increasingly drawn to specialties or subspecialties that seem to be more fulfilling and involve less commitments and responsibilities (4).
The reduction in activities offered that was a result of the European Work Time Directive (EWTD) quickly led to a 50\% cut in training courses in both theory and practice, offered at academic institutions. This led to a deficit in theoretical knowledge and technical skills (5).

The Association of Surgeons in Training (ASiT) in the UK has denounced the effects of program cuts, cuts in time and resources, and even a reduction in safety but in spite of this the Joint Committee on Surgical Training plans further cuts in training programs especially those for emergency general surgery (6).

At the same time the costs of specialist training, especially in surgical disciplines, have soared. In the UK the average cost of 1 year of surgical residency is more than £3300, whereas for medical disciplines in general the cost is at most $£ 2800$ and for anesthesia $£ 2200$, in spite of the fact that the work performed by trainees provides more income for hospitals than the cost of residents 'salaries (7).

Another effect of the cuts in programs introduced by the EWTD was the need to have more tutors in order to avoid an excessive reduction in training activities, especially hands on experience. However, this led to the risk of hiring tutors who are inadequately prepared, not sufficiently motivated, and with limited ability to teach and transmit to trainees their own practical experience. Many of these new tutors are also involved in medico-legal problems and therefore tend to avoid further responsibilities such as performing the most difficult parts of surgical procedures, and this reduces the trainees' possibilities to expand their knowledge $(2,9)$.

The result is that described by Griffiths (8): at the end of their training, only $3 \%$ of the young surgeons in Great Britain are skilled enough to perform the 6 major 
operations on their own. In addition to all these intrinsic problems regarding surgical training there are problems related to the surgeon's job. For instance, the catchment population, especially for emergency surgery, is increasingly made up of the elderly with increasingly severe chronic diseases, suffering from physical deterioration, often with fragile homeostatic mechanisms and reduced physiological reserves. These patients are often on multiple medications, especially anticoagulants, which makes emergencies especially problematic. This aging population continues to grow in numbers and is increasingly prone to require emergency treatment which often has disappointing results (10).

The problems mentioned above have led to a constant decline in the number of surgical trainees. Less and less medical graduates decide to become surgeons, not least because of the reduced appeal of this field (9) This is especially true of emergency surgery which is associated with a bad quality of life, the constant risk of being involved in medico-legal issues, and the high costs of post residency training (11)

It is important not to underestimate the difficulties in learning the new surgical procedures which are often performed by a single surgeon and therefore not widely transmissible (2). The great appeal of the new surgical subspecialties must also be taken into account. They offer surgeons a better lifestyle and the technical and technological progress made in laparoscopy, endoscopy and interventional radiology, have reduced the need for first line surgery.

Taking all these matters into account it is easy to understand why only $5 \%$ of medical graduates in the UK say they would choose emergency general surgery as a career (11). The responses to various surveys that have been carried out, especially in the UK, including the survey by Pearce et al (2016), provide further details about this difficult situation. Pearce and colleagues found that $52 \%$ of emergency surgery consultants with less than 5 years of experience and $13 \%$ of those with less than 20 years of experience do not feel optimally prepared to handle surgical emergencies. At the same time $92.4 \%$ of practicing young surgeons would have

preferred more in-depth training in emergency surgery (12).

Clearly it is essential to create a new surgical subspecialty in emergency surgery in trauma patients and non-trauma patients, focused on specific and technically advanced training; in other words what Catena et al call "the navy seals paradigm" (13). These specialist surgeons would have to be available 24 hours a day, 7 days a week, and have the following characteristics: a high level of technical and practical training, sound decision-making skills, excellent manual skills, a strong team spirit and the desire to continually improve their abilities. (14) But who should train the surgeons of tomorrow?

\section{The role of scientific societies}

We are convinced that the mission of a scientific society should be to encourage professional development and promote scientific and technical excellence in the discipline it represents. It should also make up for deficits in the training options provided by academic institutions and provide support in training young professionals.

Among the many activities of the Italian Society of Emergency and Trauma Surgery (SICUT), which include preparation of practice guidelines and annual consensus statements, as well as collaboration with other scientific societies and fostering international relationships, the development of training courses for young and also more experienced surgeons has for quite 
sometime been of key importance. Years ago, the SICUT began validating many of the courses in practical skills available in Europe, for instance, the advanced trauma operative management (ATOM) course, definitive surgical trauma care (DSTC) course, the modular ultrasound ESTES (European Society for Trauma and Emergency Surgery) course (MUSEC), and the medical response to major incidents and disasters (MRMI) course. At the same time, we took care to design and implement our own online university

courses and residential courses. The university courses were organized in partnership with numerous public and private universities in Italy and with the graduate school of health economics and management (ALTEMS) at the Catholic University of the Sacred Heart in Rome. These consisted of higher education courses, advanced courses/master classes, and first and second level masters' programs.

In addition, in partnership with universities and regional government, we organized e-learning courses in first aid, trauma surgery and emergency surgery, and, especially during the last period of the pandemic single-topic webinars and meetings with specialized programs.

\section{SICUT residential courses}

For many years we have focused on organizing hands-on training courses for young and not so young surgeons.

The first was the live surgery course in polytrauma surgery on pigs which is now being offered for the 40th time. More recently we organized a live surgery course in emergency surgery on pigs, the first course of this kind in Europe and later a course on advanced management of severe hemorrhage following chest/abdominal trauma, on human cadavers.
The live surgery course in polytrauma is organized by the SICUT and the "A.Gemelli" University Hospital, University of the Sacred Heart, in Rome. We usually offer 2 courses a year with 3-4 surgical stations, each with 4 students and 1 tutor. The average cost is ca. $€ 1300$ but there is a discount for SICUT members.

The course in emergency surgery on pigs is organized by the SICUT and the University of Camerio and is held at the veterinary hospital of the university, which is in Matelica. There are usually 3 courses a year with 2 surgical stations, each with 4 students and 1 tutor. The average cost is ca.€1300, including meals and accommodation, with a discount for SICUT members.

The program begins with laparoscopic procedures for non-trauma emergencies such as perforation, abscess, hemorrhage. In the second part of the course open procedures are performed on the chest and abdomen including lifesaving maneuvers and surgical resection, demolition and exteriorized repair.

These two courses on animal models are intended especially for young surgeons and residents in their final years of training who are often sent to us as part of exchange programs.

The course on advanced management of severe hemorrhage following chest/abdominal trauma was organized in partnership with the cadaver lab ICLO of Arezzo and Verona and with the biotechnology center of the Cardarelli hospital in Naples. Usually, 3-4 courses are held per year with 2 surgical stations, each with 4 students and 1 tutor. The cost is ca.€1800 with discounts for SICUT members and includes meals and accommodation. This course, on human specimens with the vascular tree filled with latex gel to facilitate hands on maneuvers, is not only intended for young surgeons but also for any surgeons 
who wish to refamiliarize themselves with lifesaving techniques, which are time dependent procedures that they cannot routinely practice and which they do not often have to perform. The course, which takes place in an operating room, begins with extraperitoneal pelvic packing for major pelvic hemorrhage. Then the abdomen is opened to gain control of hemorrhage from the inferior vena cava and the subdiaphragmatic aorta was clamped on the right and left.

Regarding the liver, the Pringle maneuver is performed and the liver is mobilized as much as possible followed by liver packing. In the chest, clamping of the supradiaphragmatic aorta is performed through a thoracotomy extended into a clamshell in order to perform resuscitative pericardiotomy. Then the pulmonary hilum is prepared. To treat parenchymal bleeding a tourniquet is applied followed by pulmonary hilum clamping and then a hilar twist is performed for definitive control of hemorrhage. Next, en bloc pneumonectomy is performed, then capitonnage at the hilum and tractotomy is performed for minor pulmonary injuries.

The organization of all the residential courses is similar: the first day is dedicated to theory, the procedures to be performed the next day are presented, and specific clinical cases are discussed as well as indications, appropriate treatment and decision making. The second day is dedicated to practical training in the operating room. All students in turn have to perform the procedures discussed the day before.

Both these courses are being offered for the 12th time and their popularity has been greater than expected in part because the hospitals, which cannot finance independent training courses, have assumed part of the costs. After the stop imposed by COVID-19 we are now moving full steam ahead and we plan to offer a series of courses later this year and early next year, providing the worst of the pandemic is over!

\section{Conflict of Interest}

Authors have no conflict of interest to disclose

\section{References}

1) Giulini SM, Stagnitti F. "SICUT training for professional development in acute care surgery; Introduction" Ann Ital Chir. 2019; 90:371-372.

2) Mullen M.G. et al "Declining Operative Experience for Junior-Level Residents: Is This an Unintended Consequence of Minimally Invasive Surgery?” J Surg Educ Jul-Aug 2016;73(4):609-15.

3) Mattar S.G. "General surgery residency inadequately prepares trainees for fellowship: results of a survey of fellowship program directors" Ann Surg 2013 Sep;258(3):440-9.

4) Soreide K. "Emergency surgery over 111 years: are we still at a crossroads or ready for emergency surgery 2.0?" Scandinavian Journal of Trauma, Resuscitation and Emergency Medicine 201523:107

5) Egan R.J et al."Modular emergency general surgery training: A pilot study of a novel programme " Ann R Coll Surg Engl. 2016 Sep; 98(7): 475-478.

6) Jamal M.H.et al" Effects of the reduction of surgical residents\&\#39; work hours and implications for surgical residency programs: a narrative review" BMC Med Educ 2014;14 Suppl 1, S14.

7) O'Callagan J. et al “Cross-sectional study of the financial cost of training to the surgical trainee in the UK and Ireland". BMJ open 2017; 7(11): e018086 
8) Griffiths T. C. "Does UK surgical training provide enough experience to meet today's training requirements? "BMJ Careers 2015;

9) Busemann A. et al "Principles of Teaching in Surgery - State of the Art" Zentralb Chir.2016 Jun;141(3):277-84.

10) Pearce L. et al "Surgery in the older person: Training needs for the provision of multidisciplinary care "Ann R. Coll Surg Engl 2016 Jul; 98(6): 367-370.

11) Rhiannon L.H. et al "The future of surgical training in the context of the \&\#39; Shape of Training\&\#39; Review: Consensus recommendations by the Association of
Surgeons in Training "Int J Surg 2016 Nov;36 Suppl 1: S5-S9.

12) Pearce L. et al "Emergency General Surgery: evolution of a subspecialty by stealth" World J. Emerg Surg 2016; 11: 2. 13) Catena F, et al "Emergency general surgeons: the special forces of general surgery (the; navy seals paradigm;) World J. Emerg Surg 2020 Feb 12;15 (1) :11

14) Coccolini F. et al "WSES worldwide emergency general surgery formation and evaluation project" World J. Emerg Surg 2018; $13: 13$ 